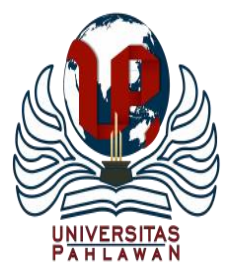

Edukatif : Jurnal Ilmu Pendidikan Volume 3 Nomor 5 Tahun 2021 Halm 2551 - 2558

EDUKATIF: JURNAL ILMU PENDIDIKAN

Research \& Learning in Education

https://edukatif.org/index.php/edukatif/index

\title{
Nilai-Nilai Pendidikan Islam dalam Berdemokrasi (Studi Kasus Di Daerah Perbatasan Indonesia-Malaysia)
}

\author{
Irpan Riadi ${ }^{1}$, Purniadi Putra ${ }^{2 凶}$, Sri Sunantri ${ }^{3}$, Arnadi $^{4}$ \\ Institut Agama Islam Sultan Muhammad Syafiuddin Sambas, Indonesia ${ }^{1,2,3,4}$ \\ E-mail : irpanriadi@gmail.com ${ }^{1}$, putrapurniadi@gmail.com² ${ }^{2}$, nantri636@gmail.com² \\ drarnadi2016@gmail.com ${ }^{4}$
}

\begin{abstract}
Abstrak
Pentingnya pendidikan demokrasi merupakan salah satu ruang lingkup kajian pendidikan Islam sehingga menjangkau penerapan pendidikan Islam sampai pada pengamalannya. Tujuan penelitian ini adalah menganalisis nilai-nilai pendidikan Islam dalam berdemokrasi masyarakat perbatasan. Metode penelitian dengan kualitatif secara deskriptif-analitik empiric. Teknik pengumpulan data menggunakan studi dokumenter, observasi, dan wawancara (in-depth interview). Teknik analisis data menggunakan content analisis dengan tahapan reduksi data, display data, penarikan kesimpulan dan verifikasi data. Hasil penelitian ini adalah pemahaman nilai-nilai pendidikan Islam dalam berdemokrasi pada konteks Pilkades berbasis nasionalisme ekuivalen dengan nilai-nilai pendidikan Islam sebab berlangsung meriah dan didukung penuh oleh segenap masyarakat dengan rasa kegembiraan, kedamaian, serta persaudaraan. Implikasi nilai-nilai pendidikan Islam pada aspek kemanusiaan, dengan keadaan kondusif yang memiliki karakter rajin gotongroyong, terbuka, selalu bermusyawarah dan cinta pada NKRI sehingga berprinsip pada persaudaraan sesama manusia (ukhuwah basyariyah), persaudaraan sesama umat beragama (ukhuwah diniyah), persaudaraan sesama umat Islam (ukhuwah Islamiyah) dan persaudaraan sesama warga negara (ukhuwah wathaniyah).
\end{abstract}

Kata Kunci: Nilai-Nilai Pendidikan Islam, Berdemokrasi, Masyarakat Perbatasan

\section{Abstract}

The importance of democratic education is one of the scopes of the study of Islamic education so that it reaches the application of Islamic education to its practice. The purpose of this study is to analyze the values of Islamic education in a border society democracy. The research method is qualitative descriptive-analytic empirical. Data collection techniques using documentary studies, observation, and interviews (in-depth interviews). The data analysis technique uses content analysis with the stages of data reduction, data display, conclusion drawing, and data verification. The result of this study is the understanding of the values of Islamic education in democracy in the context of Pilkades based on nationalism is equivalent to the values of Islamic education because it takes place lively and is fully supported by the whole community with a sense of joy, peace, and brotherhood. The implications of Islamic education values on the human aspect, with conducive conditions that have the character of diligent cooperation, openness, always deliberation, and love for the Unitary State of the Republic of Indonesia so that the principles of brotherhood among human beings (ukhuwah basyariyah), brotherhood of fellow religious people (ukhuwah diniyah), brotherhood fellow Muslims (ukhuwah Islamiyah) and brotherhood among citizens (ukhuwah wathaniyah).

Keywords: Islamic Education Values, Democracy, Border Society

Copyright (c) 2021 Irpan Riadi, Purniadi Putra, Sri Sunantri, Arnadi

$\triangle$ Corresponding author:

Email : putrapurniadi@gmail.com

DOI : https://doi.org/10.31004/edukatif.v3i5.902

ISSN 2656-8063 (Media Cetak)

ISSN 2656-8071 (Media Online)

Edukatif : Jurnal Ilmu Pendidikan Vol 3 No 5 Tahun 2021 p-ISSN 2656-8063 e-ISSN 2656-8071 
2552 Nilai-Nilai Pendidikan Islam Dalam Berdemokrasi (Studi Kasus Di Daerah Perbatasan IndonesiaMalaysia) - Irpan Riadi, Purniadi Putra, Sri Sunantri, Arnadi

DOI: https://doi.org/10.31004/edukatif.v3i5.902

\section{PENDAHULUAN}

Dalam konteks pendidikan di Indonesia memang tidak bisa terlepas dari knowledge and power (pengetahuan dan kuasa). Pengetahuan yang dapat diperoleh melalui pendidikan dan kuasa yang diemban oleh pemerintah untuk mengatur dan menentukan perkembangan peradaban bangsa Indonesia. Dengan kata lain transfer of knowledge and transfer of value menjadi tanggung jawab pemerintah untuk mensejahterakan rakyatnya.(Wijaya, 2018). Pendidikan diharapkan dapat membangun dan mengembangkan potensi manusia agar memiliki karakter, integritas, dan kompetensi yang bermakna dalam kehidupan. Oleh sebab itu pendidikan diharapkan mengarah pada pandangan dan praktek yang membangun ruang pembelajaran dan dapat memperkaya nilai-nilai kemanusiaan, keluhuran, kejujuran, dan keberadaban (Purwaningsih, 2019). Menurut Lailial Muftiah bahwa pendidikan keagamaan (Islam) adalah pendidikan yang menjadi bagian untuk menyiapkan seorang pembelajar untuk dapat menjalankan tanggung-jawab dan perannya sebagai warga negara dengan dasar penguasaan pengetahuan khusus ajaran agama yang bersangkutan (Muftiah, 2012).

Pentingnya berdemokrasi sebagai universal value tentu tidak menjadi hak kepemilikan individu maupun klaim kelompok di tengah masyarakat, tetapi merupakan "entitas" yang memiliki nilai lintas sektoral serta diperjuangkan demi kepentingan bersama (Yusuf Sukman, 2017). Secara umum bahwa demokrasi pendidikan bisa dimaknai sebagai suatu tatanan di mana nilai nilai demokrasi, seperti keadilan, musyawarah, persamaan, kebebasan, kemajemukan dan toleransi, dijadikan sebagai landasan atau asas dalam seluruh program dan praktik pendidikan. Dalam situasi saat sekarang ini banyak masalah pendidikan yang muncul, terlalu sepele dalam akibat kurang adilnya dalam memperoleh kesempatan untuk mengakses pendidikan, sampai saat sekarang ini dapat dilihat betapa banyaknya perlakuan orangtua yang selalu meyalahkan guru, kurangnya partisipasi masyarakat terhadap pendidikan. Dalam situasi seperti ini maka, terdapat suatu masalah yang berhubungan dengan nilai dan praktik demokrasi pendidikan (Daulay, 2017). Menurut e.g., Liddle, Huntington (Karman, 2015) demokratisasi disuatu negara tidak lepas dari peran agama yang menentukan perilaku politik.

Secara substansial, pendidikan tidak sebatas pengembangan intelektual manusia, artinya tidak hanya meningkatkan kecerdasan, melainkan mengembangkan seluruh aspek kepribadian manusia. Makna pendidikan yang lebih hakiki lagi adalah pembinaan akhlak manusia guna memiliki kecerdasan membangun kebudayaan masyarakat yang lebih baik dan mampu meningkatkan kesejahteraan hidupnya.(Ismail, 2016). Pendidikan merupakan proses perubahan secara berkelanjutan menuju kebaikan. Perubahan yang dihasilkan melalui kegiatan pendidikan bersifat evolusioner dan konstan. Pendidikan sebagai suatu proses pencerahan dan perubahan, maka pendidikan menjadi sebuah refleksi dan indikator dinamika suatu bangsa (Halik, 2016).

Pendidikan Islam harus berjiwa demokratis seiring dan seirama dengan tuntutan reformasi. Jika sebelum reformasi masih ada pendidikan Islam yang kurang demokratis, maka sudah saatnya budaya-budaya demokrasi itu dibudayakan dalam kultur pendidikan Islam ke depan.(Firdaus, 2016).

Paradigma sosial, budaya dan politik masyarakat dalam pelukan pendidikan Islam bisa dilihat dalam ruang lingkup pemilihan Kepala Desa di Kecamatan Paloh, Kabupaten Sambas tahun 2019, apalagi peneliti melihat diskurusus ini dalam perspektif pendidikan Islam. Sehingga peneliti disini memilih masyarakat muslim yang tentunya terlibat langsung dalam dunia pendidikan Islam dan terlibat langsung juga dalam pentas Pilkades serentak 2019. Khusus jaungkauan-lingkup (scope) dalam penelitian ini akan dijelaskan kemudian. Penekanan peneliti dalam kajian ini menganggap bahwa pendidikan demokrasi merupakan salah satu bagian penting dalam lingkup kajian pendidikan Islam, hal tersebut tidak sebatas melingkari pendidikan demokrasi hanya pada mentransfer ilmu pengetahuan dari guru ke murid, dari lembaga negara ke masyarakat. Tapi lebih jauh lagi melihat hasil penerapan sosialisasi pendidikan Islam sampai pada pengamalannya. Selama ini kajian mengenai pendidikan demokrasi, hanya digeluti oleh para sarjana yang membidani ilmu politik dan sosial. Sehingga kajian tentang pendidikan seperti telah mengalami penyususutan (contraction), karena sangat jarang 

Malaysia) - Irpan Riadi, Purniadi Putra, Sri Sunantri, Arnadi

DOI: https://doi.org/10.31004/edukatif.v3i5.902

sekali para pakar pendidikan Islam berbicara mengenai politik kebangsaan, apalagi secara khusus berbicara tentang pentas demokrasi. Lebih dari itu peneliti disini memberanikan diri untuk terlibat dalam kajian pendidikan Islam dalam demokrasi, guna menawarkan novelty pada ruang lingkup pembelajaran pendidikan Islam. Pentingnya penelitian ini adalah untuk memberikan kebermaknaan dalam persatuan dan kesatuan bangsa yang bernilai pendidikan Islam sehingga terbentuk karakter berkerjasama dalam membantu dan saling peduli sosial. Penjelasan tersebut akhirnya menarik perhatian peneliti untuk mengkaji lebih mendalam lagi mengenai nilai-nilai pendidikan Islam dalam Berdemokrasi (Studi Kasus di Daerah Perbatasan IndonesiaMalaysia) Pemilih Muslim Warga Desa Sebubus, Kecamatan Paloh Pada Pilkades 2019.

\section{METODE PENELITIAN}

Penelitian ini merupakan jenis penelitian lapangan (field research) yaitu penelitian yang dilakukan langsung ke obyek penelitian yang menggunakan analisis data studi kasus. Lokasi penelitian ini Penerapan Pendidikan Islam dalam berdemokrasi pada Pilkades Serentak 2019 di Kecamatan Paloh, Kabupaten Sambas, Khususnya pada Pemilihan Kepala Desa Sebubus dengan observasi kepada masyarakat muslim yang khususnya dijadikan sebagai informan ialah tokoh agama sebagai responden pada setia Dusun (penjelasan jumlah responden dijelaskan pada sub teknik pengumpulan data). Jenis penelitian kualitatif ini menggunakan pendekatan deskriptif-analitik. Pendekatan dengan meninjau Penerapan Pendidikan Islam dalam Demokrasi pada Pilkades Serentak 2019 dan pendekatan field ressearch yaitu pendekatan melalui proses pengambilan yang diperoleh langsung dari wawancara melalui responden dan narasumber terkait dengan fokus penelitian. Teknik pengumpulan data terbagi menjadi teknik observasi langsung, teknik observasi tidak langsung, teknik pengukuran, dan teknik studi dokumenter. Teknik pengumpulan data yang dilakukan dalam penelitian ini menggunakan teknik studi dokumenter dan teknik observasi tidak langsung. Teknik kedua ini juga merupakan aspek terpenting dalam proses pengumpulan data di lapangan, ada 11 (sebelas) partisipan yang diwawancarai secara mendalam (in-depth interview) terkait dengan konteks yang diteliti. Untuk wawancara ini menggunakan model interview terbuka berstandar yaitu interview yang mempunyai pedoman, pertanyaan bersifat terbuka, tetapi tersusun secara standar. Teknik analisis data yang digunakan dalam penelitian ini adalah (a) reduksi data yang diperoleh langsung pada sumber data yang asli, kemudian ditulis dan diketik dalam pentuk penjelasan dan laporan yang rinci dengan direduksi, dirangkum, dipilah hal-hal yang penting atau pokok, terfokus-kan pada permasalahn yang lebih penting serta disusun secara sistematis sehingga fokus permasalahan dapat terkendali dengan mudah, (b) display data seperti penjelasan mengenai gambaran umum pemerintahan Kabupaten Sambas yang penjelsannya luas dan parsial, (c) penarikan kesimpulan dan verifikasi data yakni dengan banyaknya data yang terkumpul maka ditentukan polanya, hubungan persamaannya dan hal lain yang lebih penting. Keabsahan data kualitatif dilakukan melalui; (a) observasi berlangsung secara terus menerus; b) triangulasi data dari sumber, metode dan peneliti lain; (c) pengecekan anggota (member check), diskusi teman sejawat dan pengecekan reverensi. Data penelitian ini disahkan melelui teknik triangulasi. Triangulasi adalah teknik pemeriksaan keabsahan data yang memanfaatkan sumber, metode dari sesuatu yang lain sebagai penguatan penelitian. Triangulasi sumber dilakukan dengan cara membandingkan dan mengecek kembali informasi dari informan satu dengan informan yang lain. Triangulasi metode dilakukan dengan memanfaatkan penggunaan beberapa metode berbeda untuk memperoleh informasi. Member checking dilakukan pada subjek wawancara yaitu pada saat wawancara dan melalui rangkuman hasil yang telah dibuat peneliti. 
2554 Nilai-Nilai Pendidikan Islam Dalam Berdemokrasi (Studi Kasus Di Daerah Perbatasan IndonesiaMalaysia) - Irpan Riadi, Purniadi Putra, Sri Sunantri, Arnadi

DOI: https://doi.org/10.31004/edukatif.v3i5.902

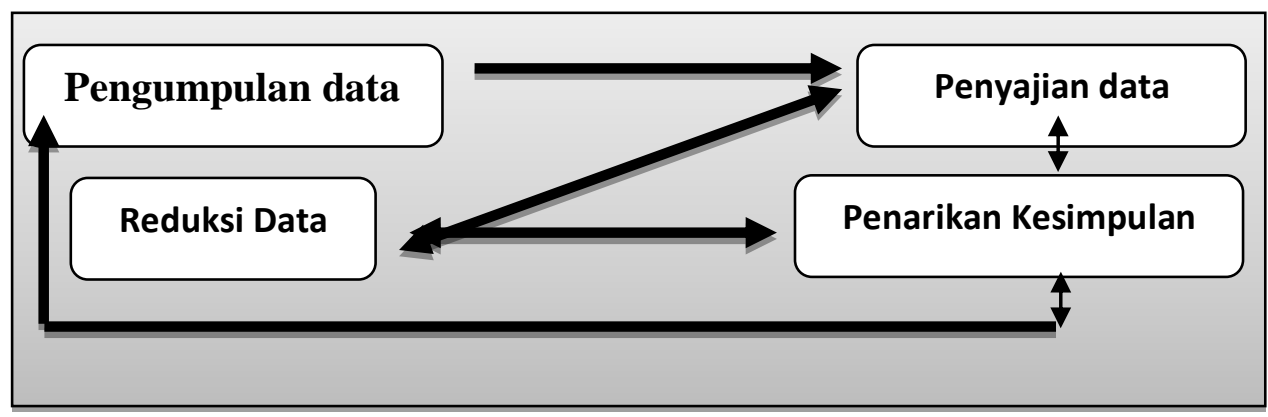

Gambar 1. Teknik analisis data

\section{HASIL DAN PEMBAHASAN PENELITIAN}

\section{Pespektif Pemahaman Nilai-Nilai Pendidikan Islam Dalam Berdemokrasi}

Pemilihan Kepala Desa Sebubus telah dilaksanakan pada hari Sabtu Tanggal 19 Oktober Tahun 2019. Pelaksanaan ini dilihat dari penerapan pendidikan Islam dalam berdemokrasi, dapat diuraikan menjadi perspektif pemahaman nilai-nilai pendidikan Islam dalam berdemokrasi dan perspektif pengamalan pendidikan Islam dalam Pemilihan Kepala Desa. Pada bagian ini, peneliti mengurai tentang pemahaman nilainilai pendidikan Islam dalam berdemokrasi. Pendidikan Islam dalam demokrasi khususnya di Indonesia dalam rancang bangunnya dapat disebut sebagai pendidikan multicultural. Secara konseptual pendidikan multikultural dalam Islam, hadir melalui prinsip, orientasi, dan implementasi atau bentuk pengembangan yang diinginkan untuk hadir dalam proses pembelajaran, karena pendidikan multikultural dalm perspektif Islam; (a) berprinsip pada demokrasi, kesetaraan, dan keadilan, (b) berorientasi kepada kemanusiaan, kebersamaan, dan kedamaian, dan (c) mengembangkan sikap mengakui, menerima, dan menghargai keragaman.(Nugroho, 2016).

Pemahaman dan pengalaman nilai-nilai pendidikan Islam di Indonesia dalam berdemokrasi secara politik disebut juga dengan pendidikan berbasis nasionalisme atau dalam bahasa lain "pendidikan yang berasaskan nilai-nilai Pancasila (Mustofa, 2017). Hal ini karena humanisasi pendidikan Islam di Indonesia dapat sejalan dengan tuntutan (demand) masyarakat atas kualitas pendidikan yang berhubungan dengan pandangan hidup dan kehidupannya, dalam arti bahwa pendidikan Islam berusaha mewujudkan ajaran Islam (tarbiyah al-Islam) ke dalam pembentukan manusia Indonesia seutuhnya.(Mustofa, 2017). Dengan demikian pendidikan Islam dan pendidikan demokrasi secara nilai ialah kompatibel dan ekuivalen, dalam arti tidak ada pertentangan,- sehingga Mustofa menegaskan bahwa nilai-nilai tersebut di dalamnya dapat ditemukan juga melalui karakteristik pendidikan yang berasaskan nilai-nilai kemanusiaan Pancasila seperti: (a) menghormati keyakinan religius, (b) menghormati martabat manusia dan hak asasisnya, (c) berwawasan kebangsaan, (d) menghargai kebebasan secara demokratis, (e) menjunjung dan menegakkan keadilan sosial.(Nugroho, 2016).

Penjelasan di atas sepadan dengan penelitian Mursidin yang telah dijelaskan sebelumnya bahwa pendidikan agama Islam berbasis nasionalisme menganut prinsip: 1) persaudaraan sesama manusia (ukhuwah basyariyah). 2) persaudaraan sesama umat beragama (ukhuwah diniyah), 3) persaudaraan sesama umat Islam (ukhuwah Islamiyah). 4) persaudaraan sesama warga negara (ukhuwah wathoniyah). Berdasarkan dari hasil wawancara Pada Pilkades di Desa Sebubus 19 Oktober Tahun 2019, masyarakat sangat menantikan pesta demokrasi tingkat Desa. Hal ini karena ada pergantian kepemimpinan setiap 5 (lima) tahun sekali, sehingga penantian ini tampak meriah dan didukung penuh oleh segenap masyarakat Desa Sebubus dan penuh kegembiraan, kedamaian, serta persaudaraan. 


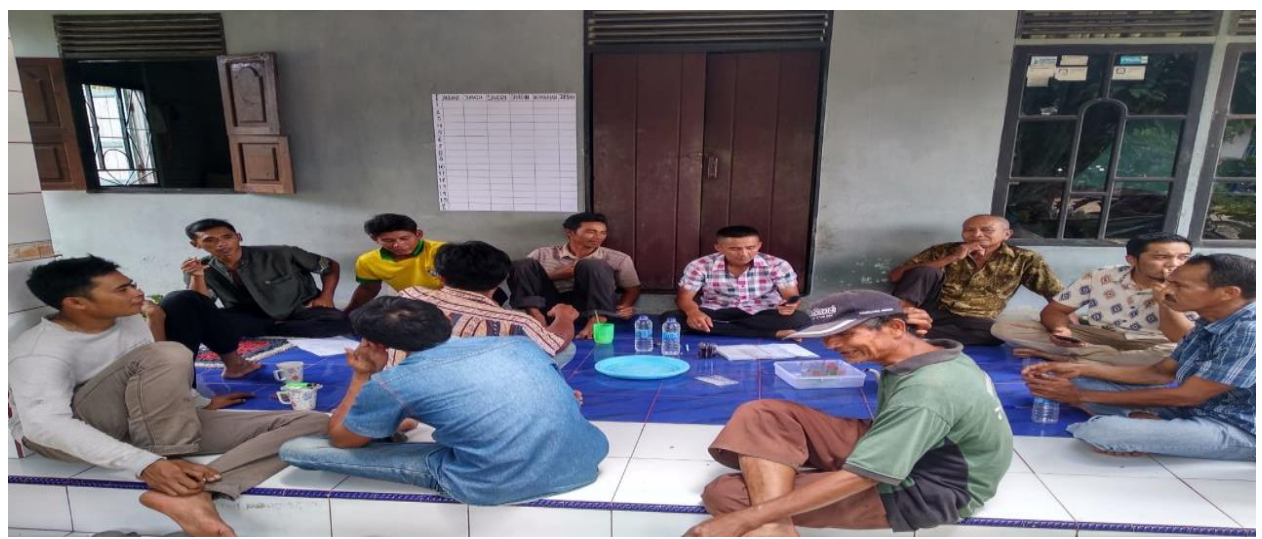

Gambar 2. Suasana kegembiraan, kedamaian, dan persaudaraan menjelang Pilkades 2019

Hal yang paling penting dalam demokrasi desa ialah keadaan kondusif dan penuh dengan kebahagiaan, sehingga penerapan pendidikan Islam lebih diarahkan pada aspek kemanusiaan. Kehidupan yang alami adalah berinteraksi, bekerjasama, dan berhubungan dengan orang lain. Mahluk hidup membentuk kelompok dan bergabung menciptakan bentuk kehidupan yang baru yang terdiri dari beragam organisme. Alam bekerjasama, tidak bersaing. Kesuksesan adalah sesuatu yang dibagi bersama (Putra, 2017). Hal ini diperkuat oleh Ramayulis (Irawan \& Hermawan, 2019) prinsip demokrasi pendidikan Islam dijiwai oleh prinsip demokrasi dalam Islam, atau dengan kata lain demokrasi pendidikan Islam merupakan implementasi prinsip demokrasi Islam terhadap pendidikan Islam. Adapun pendidikan Islam terdiri dari; (a) kebebasan bagi pendidik dan peserta didik. Kebebasan disini meliputi: kebebasan berkarya, kebebasan mengembangkan potensi dan kebebasan berpendapat, (b) persamaan terhadap peserta didik dalam pendidikan Islam. Karena, Islam memberikan kesempatan yang sama bagi semua peserta didik untuk mendapatkan pendidikan atau belajar.

Berdasarkan dari hasil penelitian bahwa masyarakat muslim Desa Sebubus pada umumnya ialah masyarakat yang rajin bekerjasama (gotong-royong), sangat terbuka dengan hal-hal baru, dan selalu bermusyawarah setiap ingin mengadakan segala sesuatu serta cinta pada Negara Kesatuan Republik Indonesia. Sehingga menjelang Pilkades di Desa Sebubus pada 19 Oktober Tahun 2019, menyambutnya dengan meriah dan antusias. Hal ini sangat berbeda sekali dengan realitas yang terjadi pada Desa Temajuk, sebuah desa wisata yang terletak di sebelah Desa Sebubus dan Ekor dari Kalimantan Barat. Pada penelitian Aslan menyebutkan bahwa terjadi pergeseran nilai yang terjadi pada masyarakat Temajuk berupa nilai modern yang cenderung materialistik dan hedonistik,(Aslan, 2019) bahkan disekolah pun demikian, seperti tergambar dalam hasil penelitiannya: "Timbulnya budaya hedonis pada kehidupan masyarakat adalah karena perubahan sosial, khususnya perkembangan teknologi, sehingga dapat merusak moral masyarakat, seperti halnya yang dialami oleh siswa-siswi Temajuk".(Aslan et al., 2019).

Masyarakat Desa Sebubus pada umumnya merupakan masyarakat yang sangat sederhana dalam berkehidupan, bahkan jarang sekali masyarakat yang cenderung tampak materialistik dan hedonistik, jika adapun masyarakat Desa Sebubus akan menjauhinya sebagai teguran atas kurangnya berkahlak dan tidak adanya nilai sosial bermasyarakat. Bahkan dari hasil wawancara mengatakan:"kite di Paloh, khususnye desa kite Sebubus rate-rate masyarakatnye hampir semuenye tau be adat, jak mun nye urang ge' dolo e berat same dipikul, ringan same dijinjing, nak urang kite Melayu, Dayak, Cine, apepun agamenye rate-rate dah gaye adatnye di Sebubus, mun nak ngendah keluar dari negare kite, kan jak geye i, soalnye negare kite to' e negare beradab".(Kita yang berada di Paloh khususnya desa kita Sebubus, rata-rata masyarakat disini hampir semuanya tahu adat, jika menurut orang jaman dulu pepatahnya 'berat sama dipikul, ringan sama dijinjing", baik itu Melayu, Dayak, Tionghoa, apapun agamanya rata-rata seperti inilah cara beradat, jikapun ada yang misalnya tidak ingin beradat (bertutur/bersikap/bertingkah sesuai tata krama) lebih baik keluar saja dari negara kita, begitulah, karena negara kita ini negara yang beradab. 
Penjelasan tersebut menandakan bahwa Desa Sebubus pada umumnya ialah masyarakat desa yang cenderung saling bekerja-sama dan peduli antara satu dan lain. Hal ini disebut dengan pengamalan masyarakat Sebubus yang sesuai dengan prinsip persaudaraa sesama manusia (ukhuwah basyariyah), persaudaraan sesama umat beragama (ukhuwah diniyah), persaudaraan sesama umat Islam (ukhuwah Islamiyah) dan persaudaraan sesama warga negara (ukhuwah wathaniyah).

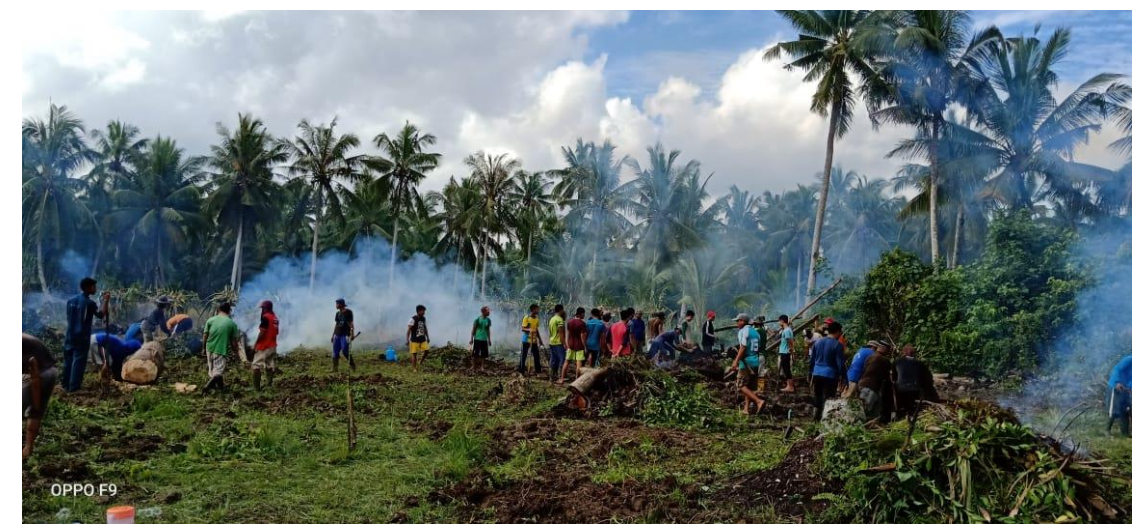

Gambar 3. Dokumentasi masyarakat bergotong-royong

Nilai-nilai pendidikan dalam bermasyarakat dan bernegara di Desa Sebubus direalisasikan dalam setiap kegiatan yang menjunjung persaudaraan. Bahkan dalam Pilkades tahun 2019, direalisasikan tanpa harus saling merendahkan martabat. Pengamalan nilai-nilai pendidikan Islam dalam berdemokrasi direalisasikan menjadi aset pemerintah Desa Sebubus, seperti yang tampak pada dokumentasi pemerintahan desa mengenai pendapatan desa, terdapat beberapa upaya yang telah dilakukan dalamr rencana pendapatan yang di targetkan dalam APBDes dapat tercapai. Upaya-upaya tersebut antara lain (PJ Kepala Desa Periode 30 Juli 2018-30 Desember 2019) sebagai berikut; (a) menggali dan memanfaatkan potensi desa, sehingga pendapatan asli desa meningkat diantaranya mengintensifkan pemasukan dari hasil usaha desa, hasil kekayaan desa, swadaya dan partisipasi, serta gotong royong masyarakat, (b) mengupayakan peningkatan pendapatan desa dari pos lainnya yang sah yaitu pos pendapatan desa yang bersumber dari Bantuan Pemerintah dan Bantuan Pihak Ketiga dan (c) Memotivasi dan meningkatkan kesadaran masyarakat agar memahami arti pentingnya pendapatan asli desa sebagai aset berharga dalam mendukung kegiatan pembangunan desa.

Setidaknya realisasi dari penerapan nilai-nilai pendidikan Islam dapat dilihat dari upaya masyarakat dan pemerintah desa di Sebubus telah selesai melaksanakan pembangunan misalnya gedung PAUD, pengamalannya yaitu untuk memberikan pendidikan formal bagi anak-anak usia dini dan Posyandu bagi masyarakat yang sangat memerlukan kesehatan dan infrastruktur lainnya yang mengakomodasi aspirasi masyarakat Desa Sebubus. Artinya pendidikan agama Islam dan pendidikan demokrasi yang terjalin dalam konteks Pilkades di Desa Sebubus secara realitas tidak terlepas dari pendidikan Islam, demokrasi, multikultural, dan nasionalisme,- atau lebih sederhana lagi ialah realitas masyarakat muslim dalam konteks pendidikan perbatasan.

Hal ini sesuai dengan hasil penelitian Makita, (2021) bahwa pendidikan adalah salah satu faktor terpenting mendorong demokrasi telah berakar di banyak masyarakat sejak demokrasi program pendidikan yang sesuai, mengajari anak-anak tentang demokrasi menghadirkan tantangan yang signifikan, karena demokrasi adalah konsep yang tidak berwujud, yang membuat anak-anak sangat sulit untuk memahami. Lembaga pendidikan idealnya menjadi ruang yang memungkinkan pertemuan perbedaan dan media untuk menjalin hubungan sosial tanpa harus dibayangi oleh prasangka. Lembaga pendidikan ternyata menjadi tempat persemaian sikap intoleransi. (Sugihartati et al., 2020), kurikulum demokrasi berfungsi, warganya harus memiliki hak dan pengajaran (Looney, 2020). 
2557 Nilai-Nilai Pendidikan Islam Dalam Berdemokrasi (Studi Kasus Di Daerah Perbatasan IndonesiaMalaysia) - Irpan Riadi, Purniadi Putra, Sri Sunantri, Arnadi

DOI: https://doi.org/10.31004/edukatif.v3i5.902

Hal ini sejalan dengan (Rosyad \& Maarif, 2020) konteks pendidikan merupakan sarana dan kesempatan palin strategis untuk mewujudkan iklim demokratisasi. Pendidikan demokrasi dapat dipahami sebagai suatu proses sosialisasi, internalisasi, dan aktualisasi konsep, dan nilai- nilai demokrasi melalui proses pembelajaran berlangsung.

\section{KESIMPULAN}

Pemahaman nilai-nilai pendidikan Islam dalam berdemokrasi yang berbasis nasionalisme karena ekuivalen dengan nilai-nilai pendidikan Islam karena belangsung meriah dan didukung penuh oleh dengan rasa kegembiraan, kedamaian, serta persaudaraan. Pendidikan Islam lebih diarahkan pada aspek kemanusiaan, sehingga kondusif dan masyarakat yang rajin gotong-royong, terbuka, selalu bermusyawarah, dan cinta pada NKRI. Prinsip persaudaraa sesama manusia (ukhuwah basyariyah), persaudaraan sesama umat beragama (ukhuwah diniyah), persaudaraan sesama umat Islam (ukhuwah Islamiyah) dan persaudaraan sesama warga negara (ukhuwah wathaniyah). Hal ini sejalan dengan pendidikan Demokrasi, sehingga tidak ada pertentangan dengan pendidikan Islam. salah satu cirinya ialah masyarakat yang selalu berkumpul dan mengadakan musyawarah bersama dengan seluruh elemen masyarakat. Pelaksanaan Pilkades Tahun 2019 di Desa Sebubus berjalan dengan baik dan tidak ada saling-penyesalan, bahkan masyarakat Desa Sebubus menikmati pesta demokrasi dan tetap menjaga persaudaraan antar tetangga dan masyarakat pada umumnya yang mempunyai latar belakang etnis, agama, dan status sosial yang berbeda. Pengamalan nilai-nilai pendidikan Islam dalam berdemokrasi ini ialah wujud dari bentuk persaudaraan antara sesama manusia (ukhuwah basyariyah), sesama umat beragama (ukhuwah diniyah), sesama umat Islam (ukhuwah Islamiyah), dan sesama warga negara (ukhuwah wathaniyah).

\section{DAFTAR PUSTAKA}

Aslan. (2019). Pergeseran Nilai di Masyarakat Perbatasan (Studi tentang Pendidikan dan Perubahan Sosial di Desa Temajuk Kalimantan Barat). IN Antasari Banjarmasin.

Aslan, Setiawan, A., \& Hifza. (2019). Peran Pendidikan Dalam Merubah Karakter Masyarakat Dampak Akulturasi Budaya Di Temajuk. Fenomena: Jurnal Penelitian, 11(1), 11-30.

Daulay, M. R. (2017). Demokrasi Pendidikan Dalam Perspektif Filsafat Pendidikan Islam. FITRAH:Jurnal Kajian Ilmu-Ilmu Keislaman, 3(1), 91. https://doi.org/10.24952/fitrah.v3i1.632

Firdaus, S. U. T. (2016). Demokrasi Pendidikan Ala Soekarno Dan Implikasinya Bagi Pendidikan Islam. AlIbrah, 1(1).

Halik, A. (2016). Paradigma Pendidikan Islam Dalam Transformasi Sistem Kepercayaan Tradisional. AlIshlah, 14(2), 285573.

Irawan, I., \& Hermawan, D. (2019). Konseptual Model Pendidikan Demokratis Perspektif Pendidikan Islam. Ta'dib: Jurnal Pendidikan Islam, 8(2), 626-631. https://doi.org/10.29313/tjpi.v8i2.5254

Ismail, M. (2016). Demokratisasi Pendidikan Islam Dalam Pandangan Kh. Abdul Wahid Hasyim. Jurnal Pendidikan Agama Islam (Journal of Islamic Education Studies), 4(2), 315. https://doi.org/10.15642/jpai.2016.4.2.315-336

Karman. (2015). Construction Of Democratic Values By Islam-Based Fundamentalist-Groups In Online Media. Jurnal Pekommas, 18(3), 181-190.

Looney, R. (2020). Creating a Democratic Classroom. Planting the Seeds of Equity: Ethnic Studies and ..., 110.

https://books.google.com/books?hl=en\&lr=\&id=HQbZDwAAQBAJ\&oi=fnd\&pg=PA96\&dq=\%22creat ive + artist $* \% 22 \% 7 \mathrm{C} \% 22$ creative+worker*\%22\%7C $\% 22$ creative+professional $* \% 22 \% 7 \mathrm{C} \% 22 \mathrm{creative}+\mathrm{c}$ lass $\% 22 \% 7 \mathrm{C} \% 22$ digital + art*\%22\%7C"digital+creat $* \% 7 \mathrm{C} \% 22$ creative+industr*\%22\%7C $\% 22$ creativ 
2558 Nilai-Nilai Pendidikan Islam Dalam Berdemokrasi (Studi Kasus Di Daerah Perbatasan IndonesiaMalaysia) - Irpan Riadi, Purniadi Putra, Sri Sunantri, Arnadi

DOI: https://doi.org/10.31004/edukatif.v3i5.902

Makita, J. (2021). Democracy Education for Children using a Cartoon Video and Mock Voting. International Journal of Asian Education, 2(2), 129-140. https://doi.org/10.46966/ijae.v2i2.169

Muftiah, L. (2012). Pola Pengembangan Kurikulum Pesantrenkasus Al-Mukhlishin Mempawah Kalimantan Barat. Jurnal Pendidikan Islam UIN Sunan Gunung Djati, 17(2), 204.

Mustofa. (2017). Pendidikan Islam Perspektif Humunisme-Pancasila. Jurnal Tarbiyah, 24(1), 157-181.

Nugroho, M. A. (2016). Urgensi dan Signifikansi Pendidikan Islam Multikultural terhadap Kompleksitas Keberagamaan di Indonesia. Attarbiyah: Journal of Islamic Culture and Education, 1(2), 179-210.

PJ Kepala Desa Periode 30 Juli 2018-30 Desember 2019. (2019). Memori Serah Terima Jabatan PJ Kepala Desa, (Sebubus: Pemerintah Desa Sebubus, 2019).

Purwaningsih, P. (2019). Implementasi Nilai-Nilai Demokrasi Dalam Pembelajaran Pendidikan Kewarganegaraan (Di Smp Islam Nurul Hidayah Reni Jaya-Depok). ... Humanis Universitas Pamulang, 202-216. http://www.openjournal.unpam.ac.id/index.php/Proceedings/article/view/5555

Putra, P. (2017). Internalisasi Pendidikan Karakter pada Pembelajaran IPA melalui Model Konstruktivisme di Madrasah Ibtidaiyah Negeri Sebebal. Muallimuna: Jurnal Madrasah Ibtidaiyah, 2(2), 75-88.

Rosyad, A. M., \& Maarif, M. A. (2020). Paradigma Pendidikan Demokrasi Dan Pendidikan Islam Dalam Menghadapi Tantangan Globalisasi Di Indonesia. Nazhruna: Jurnal Pendidikan Islam, 3(1), 75-99. https://doi.org/10.31538/nzh.v3i1.491

Sugihartati, R., Suyanto, B., Hidayat, M. A., Sirry, M., \& Srimulyo, K. (2020). Habitus of institutional education and development in intolerance attitude among students. Talent Development and Excellence, 12(1).

Wijaya, M. M. (2018). Relevansi Pendidikan Islam Demokratis Dalam Surat Ali IMRAN 159. Jurnal Pendidikan Agama Islam Universitas Wahid Hasyim Semarang, 6(2), 28-57.

Yusuf Sukman, J. (2017). Islam Dan Demokrasi Telaah Atas Komunikasi Politik Dalam Pemilihan Umum Langsung Oleh Rakyat Dalam Perspektif Sosiologis. Jurnal Komunikasi Hasil Pemikiran Dan Penelitian, 4(1), 9-15. 